\title{
Evolution of folate content during barley malt production
}

\author{
D. Koren* (1), B. Hegyesné Vecseri and G. Kun-Farkas
}

Department of Brewing and Distilling, Faculty of Food Science, Szent István University, Ménesi street 45, 1118 Budapest, Hungary

\section{ORIGINAL RESEARCH PAPER}

Received: November 30, 2020 • Accepted: February 12, 2021

Published online: April 1, 2021

(C) 2021 The Author(s)

\begin{abstract}
The aim of this research was to study the effect of micro- and industrial scale malting on the folate content of barley. Two malting barley varieties (one spring and one winter) were studied, applying the same technology. Furthermore, a roasting experiment was carried out at given temperatures for different time periods. The total folate content was determined by microbiological method. The folate content of the barleys was between 10.1 and $23.4 \mu \mathrm{g} / 100 \mathrm{~g}$ dry matter. For micro- and industrial scale, malting folate content increased 6.5-8-fold and 4-7-fold, respectively, during the malting process. An unexpected result was observed during industrial malting: the folate content increased during kilning by $18-35 \%$, unlike micro scale malting, where a $15-20 \%$ decrease was observed. Results obtained during roasting showed that folic acid content did not decrease when roasted for $20 \mathrm{~min}$ at $100{ }^{\circ} \mathrm{C}$, but it decreased linearly with increasing temperature. Folate is completely degraded in $20 \mathrm{~min}$ at $200^{\circ} \mathrm{C}$. It can be stated that barley malt can serve as a relatively good source of folate, but barley variety and malting technology have significant impact on it.
\end{abstract}

\section{KEYWORDS}

folate, barley, micro malting, industrial malting, roasting

\footnotetext{
*Corresponding author. Tel.: +36 305548402. E-mail: danikoren3@gmail.com
} 


\section{INTRODUCTION}

It is assumed that on a population level, nutritional requirements for folate cannot be completely covered by a varied diet, as recommended by national health authorities. Dietary intake is below recommendations in numerous Western countries, owing to low consumption of folate-rich foods, e.g., pulses, citrus fruits, and leafy vegetables (Ohrvik and Witthoft, 2011). With this research, we aim to study a raw material used in several food, which can potentially contribute to the folate intake.

Folate is a vitamin $\mathrm{B}$, which acts as a coenzyme in single carbon transfer reactions. It participates in the metabolism of nucleic acids and amino acids. Several vitamer forms can occur, which are the reduced derivatives of folic acid (pteroyl-L-glutamic acid, PGA). It has an important role in prevention of neural tube defects in foetus. Insufficient folate intake is also associated with megaloblastic anaemia, an increased risk of cardiovascular diseases, stroke, and certain types of cancer, and may be associated with dementia and Alzheimer's disease (Andersson et al., 2008; Hübner and Arendt, 2013). Furthermore, folate is the most important co-factor in the remethylation pathway of homocysteine. Elevated concentration of total homocysteine in blood (hyperhomocysteinaemia) is the risk factor for occlusive vascular disease (Mayer et al., 2001). Another aspect of the increasing interest in folate in terms of health promotion is the discovery that it may play an important role as an antioxidant, both by preventing the adverse effect of reactive oxygen species (ROS), as well as by inhibiting lipid peroxidation (Merola et al., 2013).

The quantification of folates in food is complicated due to the numerous forms of native folates, their instability, the complexity of food matrices, and the relatively low concentration of the analytes (Van Wyk et al., 2014). In this study the microbiological method was used. The most frequently applied microorganism, Lactobacillus rhamnosus, gives similar response to monoglutamates, diglutamates, and triglutamates, but a decreasing activity with further increase in chain length. Since folate mainly exists as polyglutamate in cereals, a certain degree of deconjugation is necessary, when barley and malt samples are examined. For this deconjugation, most often chicken or pork pancreatin is used because of their wide range of enzyme activity (e.g. protease, $\alpha$ - and $\beta$-amylase) (Ringling and Rychlik, 2017).

Cereals are considered a good source of folate. Barley is one of the most cultivated crops globally ( $12 \%$ of total cereal cultivated), ranking fourth among cereal grains after wheat, rice, and maize. Approximately $65 \%$ of cultivated barley is used for animal feed, 33\% for malting, whereas only $2 \%$ is used directly for human consumption (Idehen et al., 2017). Typical food applications of barley: pearl barley is used in soups and dressing flour; milled barley is used in baby food, bread, biscuits; malted barley is used for brewing, baking, and producing distiller's alcohols, or in milk based beverages, malt syrups, as coffee substitute, and so on (Vasan et al., 2014).

Barley is mainly used in its malted form for human consumption. The malting process usually consists of three main steps: the first is steeping to increase the moisture content of the kernels, the second is a controlled germination, where the green malt is produced, and finally kilning of the green malt. Germination and kilning have been found to change the appearance, flavour, and taste of the grain, as well as their nutritional value (Hübner and Arendt, 2013). 
There is only one scientific publication available on the evolution of folate content during malting of barley, authored by Walker (2003), where the effect of pilot-scale malting of different barley cultivars was studied on folate content. As no related information is found in the literature, our aim was to compare the evolution of folate content during industrial and pilot-scale malting, and to determine the relevant differences. The comparison of these results would be of practical use, because the great majority of malted products that are used as food ingredients are results of industrial malting. Furthermore, we aimed to study the effect of roasting on folate content, because the so called special malts, which are treated at higher temperatures, are also used for human consumption in the form of brewing malt, malted syrups, colorant in bakery products, or coffee substitute.

\section{MATERIALS AND METHODS}

\subsection{Barley samples}

For the malting experiments two malting barley varieties have been selected, the spring variety was Etincel and the winter variety was Casanova. The barleys for micro- and industrial scale malting are of the same variety, but have been harvested in successive years. The micro-scale and industrial scale maltings were carried out from the barleys cropped in 2017 and in 2018, respectively.

\subsection{Malting}

The malting was carried out in a Schmidt-Seeger micromalting plant (Bühler AG) and in an industrial malting factory. The industrial malting factory was equipped with conical steep tanks, multiple-floor circular germination, and kilning units with rotating floors and fixed helical screw turners. Samples were taken to determine folate content from barley before malting, and during malting: after steeping, every day of germination, and after kilning.

The same malting technology was applied on both micro-scale and industrial scale, which was as follows: steeping consisted of 2 wet periods, between the wet periods there was a $12 \mathrm{~h}$ of air rest, water temperature was $15^{\circ} \mathrm{C}$. The germination lasted for 5 days, the temperature was $15^{\circ} \mathrm{C}$ on the first day and was increased by $1{ }^{\circ} \mathrm{C}$ every day. Water was sprayed on the first 3 days onto the green malt regularly. The kilning began at $50{ }^{\circ} \mathrm{C}$ for $24 \mathrm{~h}$, then the temperature was raised to $85{ }^{\circ} \mathrm{C}$ continuously in the next $24 \mathrm{~h}$. After kilning the rootlets were removed. All samples were stored at $-23{ }^{\circ} \mathrm{C}$ until analysis.

\subsection{Roasting}

The roasting was carried out in a hot air fryer. Onto the false bottom $100 \mathrm{~g}$ malt was placed, and air was circulated through the malt bed for different time periods at different temperatures: for $20 \mathrm{~min}$ at $100,125,150$, and $175{ }^{\circ} \mathrm{C}$, and at $200{ }^{\circ} \mathrm{C}$ for $5,10,15$, and $20 \mathrm{~min}$.

\subsection{Moisture content}

The moisture content of the barley and malt samples was determined by an AND MX-50 Moisture Analyzer (A\&D Weighing, Tokyo, Japan). 


\subsection{Determination of folate content}

For the determination of total folate content, a microbiological microtiter plate, VitaFast ${ }^{\circledR}$, from R-Biopharm AG (Darmstadt, Germany) was used. The VitaFast ${ }^{\circledR}$ Folic Acid test was validated and certified with the licence no.100903 as a Performance Tested Method by the Association of Official Agricultural Chemists (AOAC) Research Institute. The procedure was the following: exactly $1 \mathrm{~g}$ grinded sample and $20 \mathrm{mg}$ pig pancreatin (Merck KGaA, Darmstadt, Germany) was weighed into a $50 \mathrm{~mL}$ centrifuge vial, then $40 \mathrm{~mL}$ phosphate buffer (7.8 g sodium dihydrogen phosphate dihydrate and $1 \mathrm{~g}$ sodium ascorbate in $1 \mathrm{~L}$ deionised water, $\mathrm{pH}$ adjusted to 7.2 with sodium hydroxide) was added and shaken. It was incubated for $2 \mathrm{~h}$ at $37^{\circ} \mathrm{C}$ in the dark and shaken 5 times during the incubation. Thereafter, the extract was heated for $30 \mathrm{~min}$ at $95^{\circ} \mathrm{C}$ in a water bath, chilled down quickly to below $30^{\circ} \mathrm{C}$, and centrifuged at $8,000 \times g$ for $5 \mathrm{~min}$. Finally, $150 \mu \mathrm{L}$ folic acid assay medium (included in the test kit) and $150 \mu \mathrm{L}$ standard or diluted sample was pipetted into the wells of the microtiter plate coated with $L$. rhamnosus. It was incubated at $37^{\circ} \mathrm{C}$ in the dark for $48 \mathrm{~h}$, and optical density was measured at $\lambda=600 \mathrm{~nm}$. The measurement was carried out in three parallels. All results are given in $\mu \mathrm{g} / 100 \mathrm{~g}$ dry matter (d.m.).

\section{RESULTS AND DISCUSSION}

\subsection{Folate content of barleys}

The folate contents of the spring and winter barleys cropped in 2017 (Fig. 1) were 10.1 and 17.6 $\mu \mathrm{g} / 100 \mathrm{~g}$ d.m., respectively, and of the spring and winter barleys cropped in 2018 (Fig. 2), 23.4 and $15.5 \mu \mathrm{g} / 100 \mathrm{~g}$ d.m., respectively. Differences of the folate content of the same barley cultivars cropped in successive years were also observed by Edelmann et al. (2013), who reported that environmental factors might also cause variations in folate content even regarding samples of the same cultivars. Folate content of different grains reported in the literature is shown in Table 1. Differences between the folate content of barleys found in the literature and determined

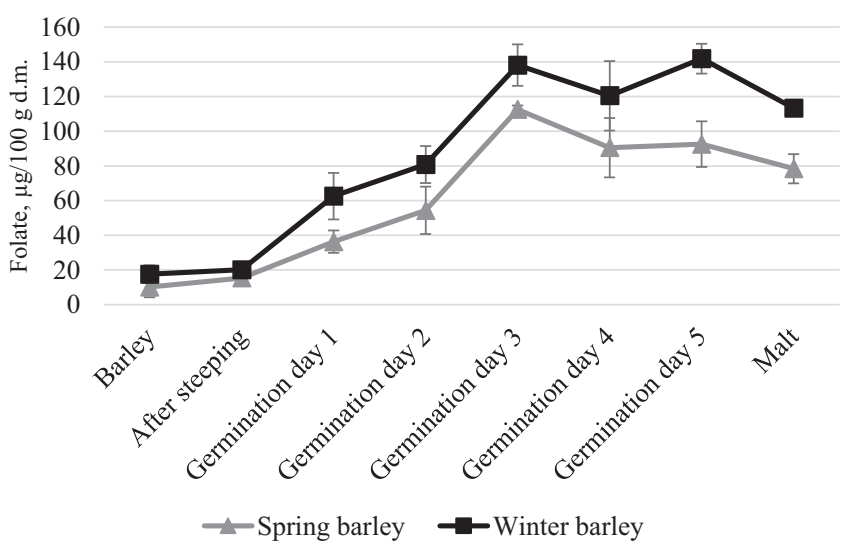

Fig. 1. Evolution of folate content during micro-scale malting of Etincel spring and Casanova winter barley (mean, sd, $n=3$ ) 


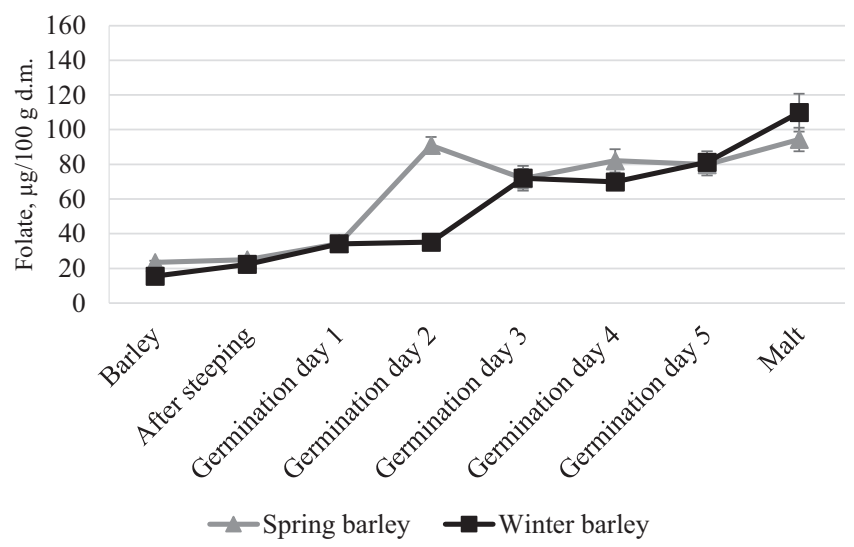

Fig. 2. Evolution of folate content during industrial scale malting of Etincel spring and Casanova winter barley (mean, sd, $n=3$ )

Table 1. Folate content of different cereals

\begin{tabular}{lcc}
\hline Sample & Folate content $(\mu \mathrm{g} / 100 \mathrm{~g}$ dry matter $)$ & Reference \\
\hline 10 barley genotypes & $51.8-78.9$ & Andersson et al. (2008) \\
5 barley cultivars in three harvest years & $56.3-77.3$ & Edelmann et al. (2013) \\
5 oat genotypes & $49.5-60.4$ & Shewry et al. (2008) \\
150 wheat genotypes & $32.3-77.4$ & Piironen et al. (2008) \\
10 rye cultivars & $63.0-78.0$ & Kariluoto, (2008) \\
\hline
\end{tabular}

by us can be explained by the fact that our research included only malting barleys, which are cultivated to be suitable for brewing, while Andersson et al. (2008) and Edelmann et al. (2013) investigated other barley varieties, as well. Compared to the folate content of oat, wheat, and rye (Table 1), the concentration of folate in the studied barleys was lower.

\subsection{Folate content of malts}

In case of both micro- and industrial scale, the malts of winter cultivars had higher folate contents than malts of the spring ones. The micro-scale malt of spring barley had a folate content of 78.4 while the winter barley $113.3 \mu \mathrm{g} / 100 \mathrm{~g} \mathrm{d.m.} \mathrm{(Fig.} \mathrm{1).} \mathrm{Concerning} \mathrm{industrial}$ malting, the results were 94.3 for the spring cultivar and $109.8 \mu \mathrm{g} / 100 \mathrm{~g} \mathrm{~d} . \mathrm{m}$. for the winter cultivar (Fig. 2). The higher folate content of the winter cultivars could be explained by the thicker husk of winter barleys, as folate accumulates mainly in the outer layers of the kernel and in the germ, thus the thicker husk can function as a protective layer (Giordano et al., 2016).

\subsection{Changes of folate content during malting}

With respect to both micro- and industrial scale malting, the folate content increased during the malting process. The folate content during micro-scale malting of the spring barley 
increased almost 8-fold, while that of the winter barley 6.5-fold (Fig. 1). Regarding industrial malting, 4-fold increase was observed in case of spring barley and 7-fold in case of the winter one (Fig. 2). It is due to the folate synthetisation of the germ during germination, as it is essential for growth and cell differentiation (Jägerstad et al., 2005), and maybe due to the enzymatic processes, which can release folate from its bound form. In the only literature available about the changes of folate content during malting, Walker (2003) observed a 4-fold increase, which equals to the lowest increase observed by us in case of the industrial malting of the spring barley cultivar.

There was a very similar trend how folate content changes during the micro-scale malting of both barleys. After a continuous increase, it reached a peak on the 3rd day of germination (spring barley: 112.5 , winter barley: $138.1 \mu \mathrm{g} / 100 \mathrm{~g}$ d.m.) and showed a 15-20\% decrease during kilning. This trend is similar to that published by Walker (2003). The loss of folate in the final malt (after kilning) compared to the green malt (the malt at the end of germination, before kilning) in case of micro scale malting can be explained by two reasons. One is the degradation of folate due to heat treatment. According to Walker (2003), folate synthesised during germination by the embryo is not stabilised by binding to proteins and may therefore be more vulnerable to heat. The other is the removal of the rootlets after kilning. In case of malts produced for brewing, the removal of the rootlets after kilning is an essential step as rootlets have a relatively high oil content, which is undesirable in brewing; but rootlets are a rich source of folate, so it could also cause the decrease of this vitamin in case of final malt compared to green malt.

With respect to industrial malting, the results showed a similar trend to micro-scale during germination, the spring cultivar had a peak on the 2 nd day of germination $(90.9 \mu \mathrm{g} / 100 \mathrm{~g}$ d.m.) and the folate content of the final malt was only slightly different from that result $(94.3 \mu \mathrm{g} / 100 \mathrm{~g} \mathrm{~d}$.m.). Regarding the winter barley, there was a greater increase between the $2 \mathrm{nd}$ and the $3 \mathrm{rd}$ day of germination, reaching a folate content of $72.0 \mu \mathrm{g} / 100 \mathrm{~g}$ d.m., this was followed by stagnation of folate content until kilning, then another increase was observed during the kilning process resulting in a folate content of $109.8 \mu \mathrm{g} / 100 \mathrm{~g} \mathrm{~d} . \mathrm{m}$. in the final malt. The increase of folate content during kilning of industrial malts was unexpected. Neither the spring nor the winter cultivars showed decrease in folate content during kilning as in case of micro-scale malting but an increase by $18-35 \%$. As the same temperatures and times were applied in both micro and industrial scale, the different trends during kilning cannot be explained by a scientifically substantiated fact. Only the different rates and methods of removal of the rootlets in the laboratory and in the industry could affect folate content, but that is unlikely to cause such a difference.

\subsection{Effect of roasting on folate content}

A large number of studies have been performed on the effect of processing on folate content of different foods, and it was proven that the food matrix highly influences folate degradation (DeSouza and Eitenmiller, 1986; Melse-Boonstra et al., 2002). For the roasting experiment Pilsner malt, produced on micro-scale, was used. In the first experiment the malt was treated at different temperatures $\left(100,125,150\right.$, and $\left.175^{\circ} \mathrm{C}\right)$ for $20 \mathrm{~min}$ in each case (Fig. 3). The results obtained showed that roasting for $20 \mathrm{~min}$ at $100{ }^{\circ} \mathrm{C}$ did not cause a decrease in folate content. This may be due to the fact that, as mentioned above, the unstable folate (which is produced by the embryo during germination) degrades during 


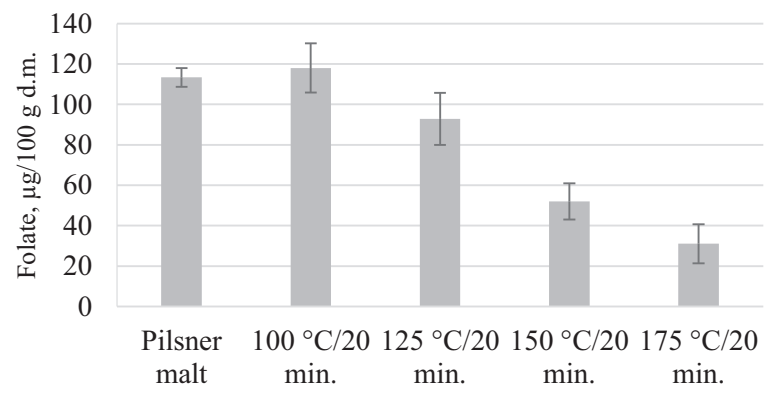

Fig. 3. Effect of roasting on the folate content of Pilsner malt for $20 \mathrm{~min}$ at different temperatures (mean, sd, $n=3$ )

kilning, and the folate in the final malt, which is structurally bound in the kernel, found in polyglutamate form bound to proteins, is more stable to heat (Walker, 2003). Thus, the Pilsner malt that was involved in the roasting experiment probably had higher thermostable folate content, because it had already been kilned, so the unstable folate had already been degraded, and the malt contained the more thermostable, structurally bound folate. With increasing temperature, the folate content decreased linearly. The folate content of the initial malt was $113.3 \mu \mathrm{g} / 100 \mathrm{~g} \mathrm{~d} . \mathrm{m}$., after the treatment for $20 \mathrm{~min}$ at $100{ }^{\circ} \mathrm{C}$, it was 118.0 , which is significantly not different, but due to the treatment at $125^{\circ} \mathrm{C}$, it decreased to 92.8 , at $150{ }^{\circ} \mathrm{C}$ to 52.0 , and at $175{ }^{\circ} \mathrm{C}$ to $31.0 \mu \mathrm{g} / 100 \mathrm{~g}$ d.m.. Kurniadi et al. (2015) reported similar result in case of mung bean flour, when due to roasting at $160{ }^{\circ} \mathrm{C}$ for $15 \mathrm{~min}$, the folate content decreased to less than one third.

Afterwards, the roasting was carried out at $200^{\circ} \mathrm{C}$ for different periods of time $(5,10,15$, and $20 \mathrm{~min}$ ) (Fig. 4). This temperature had a large effect on folate content, only $5 \mathrm{~min}$ at $200{ }^{\circ} \mathrm{C}$ decreased the folate content to about one third $(40.6 \mu \mathrm{g} / 100 \mathrm{~g} \mathrm{~d}$.m.), and in $20 \mathrm{~min}$ folate was completely degraded. These results indicate that special malts that are treated above $100{ }^{\circ} \mathrm{C}$ for different time periods suffer different degrees of folate loss. It can be stated that with increasing colour of the malt the folate content decreases.

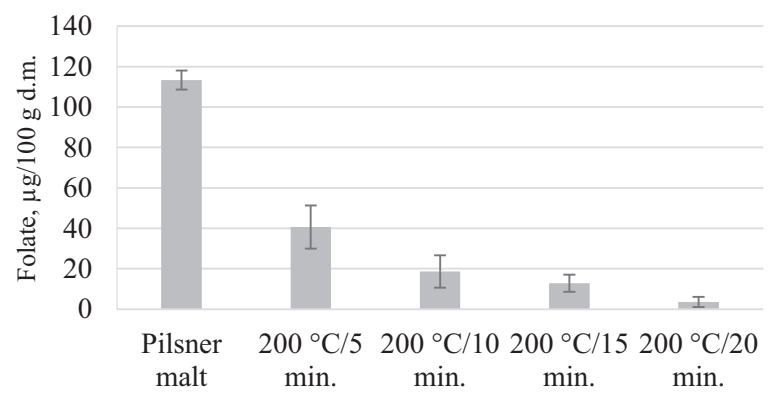

Fig. 4. Effect of roasting on the folate content of Pilsner malt at $200{ }^{\circ} \mathrm{C}$ for different time periods (mean, sd, $n=3)$ 


\section{CONCLUSIONS}

Summarising the research results, it can be stated that barley malt is a relatively good folate source, but malting can make it an even richer source of folate, which, however, can be greatly influenced by technological parameters, malting conditions, and volume (laboratory scale, industrial scale). Based on our results, the change of folate content during kilning showed the largest difference between laboratory and industrial malting. Further experiments supplemented by physiological tests would be needed to elucidate the reasons for this. From the nutritional point of view, green malt of barley, the germinated seed, would be the most beneficial to consume, but its limited shelf life and the dietary habits do not allow it to be widespread. The roasting experiments showed that at $100{ }^{\circ} \mathrm{C}$ the folate content was not adversely affected, but with increasing temperature folate content decreased continuously. From a practical point of view, as barley malt is used in several food products, it would be beneficial to apply its pale form, as the coloured types are treated at higher temperature resulting in lower folate content, however, it should be noted that technological parameters and in case of beers the yeast metabolism can greatly influence the folate content.

\section{ACKNOWLEDGEMENT}

This research project was supported by the Doctoral School of Food Sciences of Szent István University (SZIU).

\section{REFERENCES}

Andersson, A.A., Lampi, A.M., Nyström, L., Piironen, V., Li, L., Ward, J.L., and Fras, A. (2008). Phytochemical and dietary fiber components in barley varieties in the healthgrain diversity screen. Journal of Agricultural and Food Chemistry, 56(21): 9767-9776.

DeSouza, S.C. and Eitenmiller, R.R. (1986). Effects of processing and storage on the folate content of spinach and broccoli. Journal of Food Science, 51(3): 626-628.

Edelmann, M., Kariluoto, S., Nyström, L., and Piironen, V. (2013). Folate in barley grain and fractions. Journal of Cereal Science, 58(1): 37-44.

Giordano, D., Reyneri, A., and Blandino, M. (2016). Folate distribution in barley (Hordeum vulgare L.), common wheat (Triticum aestivum L.) and durum wheat (Triticum turgidum durum Desf.) pearled fractions. Journal of the Science of Food and Agriculture, 96(5): 1709-1715.

Hübner, F. and Arendt, E.K. (2013). Germination of cereal grains as a way to improve the nutritional value: a review. Critical Reviews in Food Science and Nutrition, 53(8): 853-861.

Idehen, E., Tang, Y., and Sang, S. (2017). Bioactive phytochemicals in barley. Journal of Food and Drug Analysis, 25(1): 148-161.

Jägerstad, M., Piironen, V., Walker, C., Ros, G., Carnovale, E., Holasova, M., and Nau, H. (2005). Increasing natural food folates through bioprocessing and biotechnology. Trends in Food Science and Technology, 16(6-7): 298-306. 
Kariluoto, S. (2008). Folates in rye: determination and enhancement by food processing. Ph.D. thesis. EKTseries 1420, University of Helsinki, Helsinki, Finland. http://urn.fi/URN: ISBN:978-952-10-4647-6.

Kurniadi, M., Poeloengasih, C.D., Frediansyah, A., and Susanto, A. (2015): Folate content of mung bean flour prepared by various heat-treatments. Procedia Food Science, 3: 69-73.

Mayer, Jr, O., Šimon, J., and Rosolova, H. (2001). A population study of the influence of beer consumption on folate and homocysteine concentrations. European Journal of Clinical Nutrition, 55(7): 605-609.

Melse-Boonstra, A., Verhoef, P., Konings, E.J., Van Dusseldorp, M., Matser, A., Hollma, P.C., and West, C.E. (2002). Influence of processing on total, monoglutamate and polyglutamate folate contents of leeks, cauliflower, and green beans. Journal of Agricultural and Food Chemistry, 50(12): 3473-3478.

Merola, N., Alonso, F.J.G., Ros, G., and Castón, M.J.P. (2013). Antioxidant activity comparison between [6S]-5-methyltetrahydrofolic acid calcium salt and the related racemate form. Food Chemistry, 136(2): 984-988.

Ohrvik, V.E. and Witthoft, C.M. (2011). Human folate bioavailability. Nutrients, 3(4), 475-490.

Piironen, V., Edelmann, M., Kariluoto, S., and Bedö, Z. (2008): Folate in wheat genotypes in the HEALTHGRAIN diversity screen. Journal of Agricultural and Food Chemistry, 56(21): 9726-9731.

Ringling, C. and Rychlik, M. (2017). Origins of the difference between food folate analysis results obtained by LC-MS/MS and microbiological assays. Analytical and Bioanalytical Chemistry, 409(7): 1815-1825.

Shewry, P.R., Piironen, V., Lampi, A.M., Nyström, L., Li, L., Rakszegi, M., and Delcour, J.A. (2008). Phytochemical and fiber components in oat varieties in the HEALTHGRAIN diversity screen. Journal of Agricultural and Food Chemistry, 56(21): 9777-9784.

Van Wyk, J., Dolley, L., and Mshicileli, N. (2014). HPLC analysis of vitamin B1, B2, B3, B6, B9, B12 and vitamin C in various food matrices. In: Zuo, Y. (Ed.). High-performance liquid chromatography (HPLC): principles, practices and procedures. Nova Science Publishers, New York.

Vasan, A., Mani, M., and Boora, P. (2014). Barley foods and health: opportunities ahead. In: Proceedings of the 2014 international conference on intelligent agriculture (IPCBEE), IACST Press Singapore, 63: 88-93.

Walker, C. (2003). The folate content of malted products: strategies for improvement. HGCA project report.

Open Access. This is an open-access article distributed under the terms of the Creative Commons Attribution 4.0 International License (https://creativecommons.org/licenses/by/4.0/), which permits unrestricted use, distribution, and reproduction in any medium, provided the original author and source are credited, a link to the CC License is provided, and changes - if any - are indicated. (SID_1) 